\title{
Characteristics of Conversation in Patients with Right Hemisphere Damage
}

\author{
Hye Yeong Jeong, ${ }^{\mathrm{a}}$, Yeo Jin Kim ${ }^{\mathrm{b}}$, Ji Hye Yoon ${ }^{\mathrm{c}}$, Jieun Choi ${ }^{\mathrm{d}}$ \\ ${ }^{a}$ Department of Speech Pathology, Graduate School of Health Sciences, Hallym University, Chuncheon, Korea \\ ${ }^{b}$ Department of Neurology, Chuncheon Sacred Heart Hospital, Chuncheon, Korea \\ 'Division of Speech Pathology and Audiology, Hallym University, Chuncheon, Korea \\ ${ }^{d}$ Department of Speech-Language Pathology and Audiology, Graduate School of Hallym University, Chuncheon, Korea
}

Correspondence: Ji Hye Yoon, $\mathrm{PhD}$

Division of Speech Pathology and Audiology,

Hallym University, 1 Hallimdaehak-gil, Chuncheon

24252, Korea

Tel: $+82-33-248-2224$

Fax: +82-33-256-3420

E-mail: j.yoon@hallym.ac.kr

Received: April 3, 2019

Revised: May 2, 2019

Accepted: May 17, 2019

This research was supported by Hallym University Research Fund in 2019 (No. HRF-201903-009)

This research was the National Research Foundation of Korea grant funded by the Korean government (No. NRF-2014S1A5A2A03065709).
Objectives: The right hemisphere has been established to be responsible for the pragmatic aspects of language, and for controlling the use and application of language. This study aimed to investigate the characteristics of conversation and topic manipulation in patients with right hemisphere damage (RHD). Methods: This study involved 24 subjects: 12 with right hemisphere cerebral infarction and 12 normal adults matched for sex, age, and education level. The data were collected using a structured protocol, and the collected data were analyzed by conversational participation indexes (number of turn-taking and frequency of utterances per turn), topic manipulation indexes (total number of total topics, frequency of turns per topic, and rate of topic initiation, rate of topic maintenance, and rate of topic switching), and conversational breakdown indexes (rate of overlap and rate of turn interruption). Results: There was no significant difference in the conversational participation indexes between the two groups. In terms of the topic manipulation indexes, the RHD group showed lower topic manipulation ability than did the normal adult group. There was no significant difference in the conversational breakdown indexes between the two groups. Conclusion: This study is significant as it identified the characteristics of conversation and topic manipulation ability in patients with RHD who had difficulty in pragmatic language, and provided baseline evidence for the assessment of and intervention for patients with RHD.

Keywords: Right hemisphere damage, Conversational participation, Topic manipulation, Conversational breakdown
사람의 뇌는 좌반구와 우반구로 구성되며, 각각의 반구는 그 기 능과 역할이 특성화되어 있다고 알려져 왔다. 일반적으로 우반구 는 언어적 요소보다는 언어 외적 요소를 담당하여 은유, 관용어, 속담과 같은 비유 언어를 처리하거나 운율(prosody) 등을 처리한 다(Kim \& Choi, 2009; Zaidel, Kasher, Soroker, \& Batori, 2002). 우 반구가 손상되면 언어의 사용 및 활용을 관장하는 화용적 측면에 서 어려움을 보이며(Brookshire, 2014) 이와 더불어 무시증(neglect), 질병불각증(anosognosia), 주의력(attention) 저하, 감정처리 능력 결함 등의 문제를 동반하기도 한다(Brookshire, 2014; Cherney \& Halper, 2001; Marotta, McKeeff, \& Behrmann, 2003). 이러한 우반 구 손상의 인지적 증상들은 우반구 손상 환자(right hemisphere damage, RHD)의 의사소통 능력에 영향을 줄 수 있다. 가령, 주의 력 장애는 의사소통 시 제시되는 정보의 이해를 방해하고 상대방 과의 상호작용 시 적절한 반응을 유지하며 이어나가지 못하도록 한 다(Brookshire, 2014). 또한 감정인식 및 표현의 결함은 타인의 의도 나 음성의 어조를 이해하지 못하게 하고 자신의 감정 등을 표현하 기 위해 억양이나 표정 변화를 활용하는 것을 어렵게 한다(Brookshire, 2014; Jang \& Choi, 2010; Shapiro \& Danly, 1985).

$\mathrm{RHD}$ 환자들의 의사소통 능력 중 특히 두드러지는 결함은 담화/ 화용 능력의 저하이다. 이들은 같은 말을 반복하며 혼자 과도하게 말을 많이 하고, 정상 성인보다 어휘를 많이 사용하나 전달하는 양 은 적고 작화증(confabulation)을 보이기도 한다. 특히 대화 상황에 
서는 청자를 고려하지 못하고 맥락에 맞지 않는 부적절한 말을 하 며 주제를 적절하게 유지시키지 못하여 주제에서 벗어난 발화를 산출한다. 또한 대화 순서를 지키지 못하여 말을 갑자기 시작하거 나 끝내기도 한다(Diggs \& Basili, 1987; Jang \& Choi, 2010; Lee \& Kim, 2011; Rehak, Kaplan, \& Gardner, 1992; Tompkins, 2012; Tompkins \& Flowers, 1985). 비유 언어(은유, 관용어, 속담) 사용에서는 문자에 함축되어 있는 의미를 이해하지 못하고 문자 그대로의 뜻으 로만 이해하여 문맥의 의미를 파악하는 데 어려움을 보이기도 한 다(Ahn, 2008; Kim \& Choi, 2009; Lee, Lim, \& Hwang, 2009).

Woo와 Kim (2017)은 RHD 환자들을 대상으로 최근 국내/외 인 지-의사소통 연구 동향을 살펴보았는데 국외에서는 서술담화(narrative)를 이용하여 유도된 일련의 이야기를 산출하도록 하거나 (Marini, 2012), 절차 설명하기 및 동화 이야기를 통해 RHD 환자의 저하된 담화 수행 능력을 보고하였다(Bartels-Tobin \& Hinckley, 2005). 그 외에도 그림설명하기 과제를 이용하여 RHD 환자의 저하 된 정보전달 능력을 보고한 연구가 있었다(Joanette, Goulet, Ska, \&

Nespoulous, 1986; Marini, Carlomagno, Caltagione, \& Nocentini, 2005). 국내에서는 비유 언어에 관한 연구가 가장 많은 비중을 차지 하였고, 담화 특성에 대한 연구가 그 뒤를 이었다(Ahn, 2008, 2011; Kim \& Choi, 2009; Lee, Kim, \& Ahn, 2015; Lee et al., 2009; Seong \& Kim, 2015; Sohn, Kim, \& Park, 2007). RHD 환자를 대상으로 담 화를 살펴본 연구로는 그림 설명하기와 절차 설명하기 과제를 이용 하여 RHD 환자의 정보전달 능력과 문장 간의 결속을 살펴본 연구 가 있었고(Seong \& Kim, 2015) 'cookie theft' 설명하기 과제를 이용 하여 담화상의 주요 개념을 분석한 연구가 있었다(Sohn et al., 2007). 그 외에 흥부와 놀부 이야기를 이용하여 담화상에서의 양적, 질적 인 특성을 확인하는 연구가 진행되었다(Baik, 2004).

그러나 앞서 언급된 선행연구의 담화과제들은 주로 제시된 특정 맥락 내에서 발화를 산출하는 과제(그림설명, 절차설명, 이야기설 명)이기 때문에 실제 의사소통 상황에서 보일 수 있는 RHD 환자 의 의사소통 결함을 살펴보기에는 어려움이 따른다. 이와 같은 맥 락으로 국외에서는 RHD 환자를 대상으로 대화 과제를 활용한 연 구가 진행되었다(Brady, Mackenzie, \& Armstrong, 2003; Chantraine, Joanette, \& Sja, 1998; Hird \& Kirsner, 2003; Kaplan, Brownwell, Jacobs, \& Gardener, 1990; Kennedy, Strand, Burton, \& Peterson, 1994; Kennedy, 2000; Prutting \& Kirchner, 1987; Rehak et al., 1992). RHD 환자는 정상인보다 대화 상대자에 대한 반응이 더 늦 고, 주제에 벗어나는 발화를 산출하거나 말을 지나치게 많이 하며 (Prutting \& Kirchner, 1987) 대화 주고받기의 빈도는 더 많으나, 대 화차례당 발화수는 적었다(Kennedy et al., 1994). 그러나 국내의
경우에는 앞서 언급한 설명이나 이야기 담화 특성과 간접 화행 능 력을 살펴본 연구(Jang \& Choi, 2010)는 보고되었으나, 자연스러운 맥락을 살펴볼 수 있는 대화를 주제로 한 연구는 제한되어 있었다.

대화란 두 명 이상의 화자와 청자 내에서 자연스럽게 이루어지는 언어적 교환(Lee \& Lee, 2013; Lund \& Duchan, 1993)으로 맥락 내 자연스러운 의사소통 능력을 살펴볼 수 있는 방법 중에 하나이다. 한 개인은 다른 한 개인 또는 다수와의 관계를 맺기 위해 대화를 하 면서 눈 맞춤을 하고 공통된 주제에 관심을 기울이며, 정보 및 감정 등을 공유함으로써 완만한 유대관계와 사회적인 관계를 형성할 수 있다. 대화를 수행하기 위해선 의도를 가지고 대화에 참여해야 한 다는 가정하에 다음의 두 가지 요소가 필요하다. 먼저 상대방과의 '대화차례 주고받기(conversational turn-taking)' (Choi \& Lee, 2013; Prutting \& Kittchner, 1987)는 화자와 청자가 번갈아 가며 말하는 것(Kim \& Lee, 2007)으로 대화자는 너무 길지 않은 차례를 가져야 하고, 대화 상대자는 차례에 끼어드는 등의 방해가 적어야 한다 (Owens, 2004). 다음으로 맥락에 따라 주제를 적절하게 다루는 '주 제 운용능력(topic manipulation skills)' (Craig \& Evans, 1989; Mentis, 1994)이 요구된다. 이 능력에는 대화의 주제 개시 및 유지, 변경 등의 하위 요소가 포함된다(Brinton \& Fujiki, 1984; Kertoy \& Vetter, 1995; Prutting \& Kittchner, 1987). 따라서 대화 과제는 절차 및 이야기 담화와 비교하여 문맥 내 언어 사용을 보다 더 잘 살펴볼 수 있게 하며, 자연스러운 맥락을 통해 대상자가 산출한 발화 특성까 지 파악할 수 있게 하므로 의사소통 평가에 있어 유용한 평가 지표 로 사용될 수 있다(Yorkston \& Beukelman, 1980).

현재 국내에는 RHD 환자를 평가하기 위한 진단 도구가 마련되 어 있지 않아, 평가 시 좌반구 손상 환자를 대상으로 한 기존의 진 단 도구를 활용하기도 한다. 그러나 RHD 환자 집단의 경우, 기본적 인 언어 능력에서 어려움을 보이지 않기 때문에 언어평가 시 실어 증 소견이 두드러지지 않아 정상으로 간주되는 등(Woo \& Kim, 2017) 이들이 가지는 의사소통 특성이 면밀히 드러나지 않았다. 이 러한 이유로 화용 언어적 측면의 의사소통 중재가 필요한 경우가 있음에도 불구하고 RHD 손상 환자의 의사소통 문제는 상대적으 로 미비하게 다루어졌다. 또한 RHD 환자를 대상으로 한 그간의 선 행연구들은 서로 다른 양상을 보이는 뇌출혈과 뇌경색을 하나의 집단으로 포괄하였으며 발병 후 경과일수가 며칠에서 몇 개월까지 이르는 대상자를 포함하였다(Baik, 2004; Jang \& Choi, 2010; Seong \& Kim, 2015). 그러나 뇌기능 연구에 있어서 뇌의 손상 시기와 경과 기간은 결과에 영향을 미칠 수 있는 주요한 요인이 되므로(Bryan \& Hale, 2001) 뇌손상에 따른 기능 저하 여부가 가장 두드러지는 시 기에 국한하여 뇌기능을 확인할 필요가 있다. 뇌경색의 경우, 급성 
기가 지난 이후에는 신경학적 회복 및 기능적 회복에 따라 발병 당 시에 나타난 기능 장애를 어느 정도 회복하게 된다(Anderson, Bourestorn, Greenberg, \& Hildyard, 1974; Coq \& Xerri, 1999). 또한 일 정 기간이 지나게 되면 손상 시 나타날 수 있는 증상과 더불어 후유 증 양상이 함께 나타날 수 있다. 따라서 만성 환자를 대상으로 하는 경우 뇌의 직접적인 기능보다는 뇌경색의 후유증을 확인하는 연구 가 될 가능성이 있고, 기능 소실과 회복의 혼재로 인해 순수한 뇌기 능 손상으로 인한 특성이 면밀하게 드러나지 않을 가능성이 있다. 그뿐만 아니라 뇌경색이 발현된 환자는 급성기에 내원하여 평가가 의뢰되는 경우가 많다. 이러한 맥락에서 급성기의 언어 문제를 확인 하고 발병 초기의 의사소통 능력을 살펴보는 것은(Bryan \& Hale, 2001; Jorgensen, Nakayama, Reith, Raaschou, \& Olsen, 1996) 대화 능력에서 우반구가 가지는 역할을 확인할 수 있다는 측면에서 매 우 중요하다. 이에 본 연구에서는 좌반구 언어평가로 선별되지 않는 우반구 환자의 평가를 위한 근거를 마련하고 나아가 중재 방향성 에 도움을 주기 위해 발병 후 경과일수 일주일 이내의 우반구 급성 기 뇌경색 환자를 대상으로 구조화된 대화 과제를 시행하였다. 그 리고 정상 통제군과 비교하여 대화 참여, 주제 및 방해 지표에서 관 찰되는 의사소통 특성을 살펴보고자 하였다.

\section{연구방법}

\section{연구대상}

본 연구의 대상은 춘천지역 소재의 종합병원 신경과에 내원한 만 50-80대의 RHD 환자 12 명과 성별, 연령, 및 교육년수를 일대일 로 대응시킨 동일 지역에 거주하는 정상성인(normal adults, NA) 12 명으로 총 24 명을 대상으로 하였다. 연구 대상자는 공통으로 (1) 한국어를 모국어로 습득하고, (2) 과제 수행이 가능하도록 심각한 말 장애(motor speech disorder)가 없어야 하며, 정상 청력과 시력
을 가진 자로 하였다. (3) 또한 한국형 간이정신상태검사(Korea-Mini Mental State Examination, K-MMSE; Kang, 2006) 결과, 연령 및 교육년수에 따른 정상규준에 속하여야 하며, (4) 단축형 노인우울 척도(Short form Geriatric Depression Scale, SGDS; Kee, 1996)를 실시하였을 때, 정상범주(8점 이하)에 속하는 대상자만 연구에 참 여시켰다. (5) 에딩거 손잡이 목록(Edinburgh Handedness Inventory; Oldfield, 1971) 평가 결과, 주된 손잡이가 오른손잡이이며, (6) 실어증-신경언어장애 선별검사(Screening Test for Aphasia \& Neurologic-communication Disorders, STAND; Kim, Heo, Kim, \& Kim, 2009)의 Oral Language Index (OLI) 영역에서 연령과 교육년 수에 근거하여 정상으로 판정된 자만 포함시켰으며, (7) 건강선별설 문지(Christensen, Multhaup, Nordstrom, \& Voss, 1991)를 실시하 여 인지능력에 영향을 주는 정신적, 신경학적 문제가 없고, (8) 우뇌 손상 환자의 경우, 신경과 전문의로부터 우반구 뇌경색으로 진단 받은 발병 후 경과일수 7일 이내의 급성기 뇌경색(acute brain infarction patients) (Jauch et al., 2013) 환자만을 대상으로 하였으며, 본 연구의 IRB (한림대학교 춘천성심병원 생명윤리위원회 201803-019) 조항에 근거하여 전문의가 모니터링하는 상황에서 환자의 상태가 불안정하지 않은 대상자만 포함시켰다. 연구대상자에 대한 두 집단 통계분석 결과, 연령, 교육년수, SGDS, K-MMSE, STAND 모두 유의한 차이가 나타나지 않았다. 이에 대한 연구대상자 정보 는 Table 1과 같으며, RHD 환자의 상세 정보는 Appendix 1과 같다.

\section{자료수집 도구 및 절차}

자연스러운 맥락 내 대화를 수집하기 위해 선행연구들에서는 일 상생활 속에서 친숙한 주제(가족, 학교, 취미)를 토대로 구조화된 절차를 사용하여 대화를 수집하였다(Brinton, Fujiki, \& Powell, 1997; Evans \& Craig, 1992). 이러한 시도의 일환으로 국내에서도 그 절차를 수정 및 보완하여 한림 대화·화용프로토콜이 개발되었

Table 1. Participants' characteristics

\begin{tabular}{|c|c|c|c|c|}
\hline & NA group ( $N=12$ ) & RHD group ( $N=12$ ) & $U$ & $p$-value \\
\hline \multicolumn{5}{|l|}{ Gender } \\
\hline Male & 5 & 5 & & \\
\hline Female & 7 & 7 & & \\
\hline Age (yr) & $66.25 \pm 10.55(50-82)$ & $67.17 \pm 11.01(55.0-83.3)$ & 71.0 & .977 \\
\hline Education (yr) & $10.08 \pm 5.16(2.0-18.0)$ & $9.25 \pm 4.95(2.0-18.0)$ & 63.0 & .630 \\
\hline SGDS & $0.75 \pm 0.96(0.0-2.0)$ & $1.08 \pm 1.24(0.0-3.0)$ & 61.5 & .551 \\
\hline K-MMSE & $28.58 \pm 1.16(27.0-30.0)$ & $28.67 \pm 0.88(27.0-30.0)$ & 67.5 & .799 \\
\hline STAND & $19.33 \pm 0.88(18.0-20.0)$ & $19.67 \pm 0.49(19.0-20.0)$ & 60.0 & .514 \\
\hline
\end{tabular}

Values are presented as mean $\pm \mathrm{SD}$ (range).

NA= normal adults; RHD = right hemisphere damage; SGDD = Short from Geriatric Depression Scale; K-MMSE= Korean version-Mini Mental State Exam; STAND = Screening Test for Aphasia \& Neurologic-communication Disorders. 
다(Choi \& Lee, 2013, 2015; Heo \& Lee, 2012; Hong \& Lee, 2016; Park, Choi, \& Lee, 2017). 이 프로토콜은 대화 내 자연스러운 맥락 을 고려하여 친숙한 주제로 검사자와 연구 대상자가 일대일로 진행 하고, 검사자의 반응이 대화에 미치는 영향을 최소화하기 위하여 반응 절차를 구조화한 것으로 일반아동이나 청소년뿐만 아니라 자폐나 언어학습부진장애 아동들을 대상으로 활용되었으며(Choi \& Lee, 2013, 2015; Heo \& Lee, 2012; Hong \& Lee, 2016; Park et al., 2017; Yang, Lee, Choi, \& Yoon, 2018), 최근에는 전두측두치매 환자 의 대화 능력을 확인하기 위한 연구도구로 활용되어 성인 대상으로 의 적용 가능성이 탐색되었다(Min, Yoon, $\mathrm{Na}, \&$ Lee, 2018). 이에 본 연구에서는 이 프로토콜의 절차(Choi \& Lee, 2013; Heo \& Lee, 2012; Park et al., 2017)를 활용하여 대화 자료를 수집하였다.

연구의 대화 주제는 '가정생활', '여가생활', '기타/친구'로 총 세 가지이며 주제는 대상자들이 일상생활에서 익숙한 주제로 선정하 였다. 대화의 자발적인 주제 개시를 확인하기 위해서 '가정생활', '여 가생활' 주제에서는 각 주제 관련 사진을 4장씩 준비하였고, 사진 은 주제에 따라 각각의 봉투에 담아 준비하였다. '기타/친구' 주제는 앞서 제시한 주제(가정생활, 여가생활)에서 충분히 프로토콜의 절 차가 익숙해졌기 때문에 주제의 맥락에 대해 제공되는 별도의 사진 없이 먼저 주제를 구두로 개시하여 준 뒤, 대화를 하였다. 제공된 사 진의 크기는 세로 $170 \mathrm{~mm}$, 가로 $220 \mathrm{~mm}$ 였다. 대화를 통해 수집된 모든 발화는 녹음전용 MP3 (ICD-TX 800)를 사용하여 녹음하였다.

본 연구 진행에 앞서 연구절차의 적절성을 확인하기 위해 예비연 구를 실시하였다. 먼저 제 1 저자는 프로토콜의 저자로부터 한림 대 화.화용프로토콜의 대화 수집 절차를 구체적으로 훈련받은 후 절 차에 따라 20-70대 정상 성인을 대상으로 대화를 수집하였다. 예비 연구를 통해 수집된 대화의 절차와 대화 분석방법에 대해 제 1 저자 와 프로토콜의 저자가 함께 검토하였으며 오류가 있는 부분은 수 정 및 보완하여 절차에 대한 적합성을 충분히 검토한 후 본 연구를 진행하였다.

본 연구의 절차는 다음의 순서로 구성되었다. 먼저 대상자와 간 단한 질문 등을 통하여(예: 오늘 기분은 어떠세요?) 친밀감을 형성 하는 시간을 가졌다. 이후 검사자는 과제에 대한 지침을 설명하여 준 뒤, 과제 수행에 대해 대상자가 이해하였다고 판단되면 '가정생 활', '여가생활'에 주제에 해당하는 사진이 들어있는 봉투를 대상자 에게 제공하고 대상자가 한 가지 봉투를 먼저 선택하게 하였다. 검 사자는 대상자가 각 주제에 들어있는 4장의 사진을 모두 본 것을 확인하고 사진을 치운 뒤, 대상자가 자발적으로 개시할 수 있는 대 화의 기회를 제공하였다. 대화 개시를 3초 이내에 하지 않을 경우, "가정생활과 관련된 것이었지요.", "여가생활과 관련된 것이었지
요."라고 주제를 언급해 주었다. 주제를 언급하였음에도 불구하고 반응이 없을 경우, 해당 주제에 해당하는 소질문("가정생활은 어 떠세요?”)을 통해 질문하였다. 대상자가 대화를 계속 이어나가면 검사자는 중립된 반응(“그렇죠.”, "네.”)으로 호응해 주었으며 대화 를 지속하지 못하거나 3초 이상의 쉼이 있는 경우에는 대상자가 앞 서 언급하였던 발화를 억양을 올리는 형태로(계속 대화가 진행되 는 것을 알리는) 반복해 주었다. 이후에도 발화를 이어가지 못하거 나 3 초 이상의 심이 있는 경우에는 “그리고요?”, “또요?”와 같이 대 화를 촉진하여 지속할 수 있도록 하였다. 대상자가 발화에 끝맺음 을 나타내는 발화 또는 행동을 보이면 준비한 다음 소주제로 넘어 가 동일하게 대화를 진행하였다. 사진을 보고 주제에 대해 대화한 두 가지의 이야기가 모두 끝나면 마지막 주제인 '기타/친구'의 주제 로 세 가지의 소질문을 통해 사진자료 없이 대화를 유도하였다. 마 지막 주제 또한 앞서 언급한 절차대로 동일하게 진행하였고 모든 소주제가 종결되면 프로토콜 종결을 대상자에게 알림으로써 모든 대화 절차를 마쳤다.

\section{자료 전사 및 분석}

수집된 모든 대화 자료는 일주일 이내 전사하였으며, 전사된 발 화 중 이해하지 못하거나 알아듣지 못한 발화 또는 자동 구와 같이 화용적 측면으로 분류되지 않는 발화는 제외하였다(Kim \& Lee, 2007). 분석은 Min 등(2018)과 Yang 등(2018)의 연구에 근거하여 '대화참여지표', '주제운용지표', '대화방해지표'로 나누어 분석하 였다. 수집된 발화는 Kim (1997), Owens (2010)의 발화구분 원칙 에 따라 구분하여 전사하였고(Appendix 2), 대화차례는 Heo와 Lee (2012)의 연구를 기반으로 하여 구분한 뒤 분석하였다(Appen$\operatorname{dix} 3$ ). 대화차례를 기준으로 하여 주제운용지표와 대화방해지표 를 살펴보았는데, '대화 주제'의 경우 Park 등(2017)의 연구에 따라 주제의 정의 및 세부원칙을 따랐으며(Appendix 4), 세부적인 유형 별 정의 및 원칙은 Choi와 Lee (2013) 연구를 기반으로 분석하였다 (Appendix 5). ‘대화방해'의 경우, Choi와 Lee (2013) 연구에 근거하 여 대화차례 중 중첩을 보인 비율과 중단을 보인 비율을 각각 측정 하였다(Appendix 6). 각 측정치에 대한 분석방법은 Table 2에 제시 하였다.

\section{신뢰도}

신뢰도 검증을 위하여 자료 분석에 대한 두 분석자 간 일치율을 산출하였다. 제 1 분석자는 2 급 언어재활사 자격증을 소지하고 2 년 이상의 임상 경력이 있는 언어병리학을 전공한 연구자이며, 제2분 석자는 2 급 언어재활사 자격증을 소지하고 언어병리학을 전공하 
Table 2. Measurements of conversation performance

\begin{tabular}{ll}
\hline & \multicolumn{1}{c}{ Measurement } \\
\hline $\begin{array}{l}\text { Conversational participation indexes } \\
\text { Number of turn-taking }\end{array}$ & $\begin{array}{l}\text { Total number of turn-takings } \\
\text { Total utterances/Total frequency of turn }\end{array}$ \\
$\begin{array}{l}\text { Frequency of utterances per turn } \\
\text { Topic manipulation indexes }\end{array}$ & Number of total topics \\
$\begin{array}{l}\text { Number of topics } \\
\text { Frequency of turns per topic }\end{array}$ & Total topics/Total frequency of turn \\
$\%$ of topic initiation & (Total topic initiation/Total frequency of turn) $\times 100$ \\
$\%$ of topic maintenance & (Total topic maintenance/Total frequency of turn) $\times 100$ \\
$\%$ of topic switching & (Total topic switch/Total frequency of turn) $\times 100$ \\
Conversational breakdown indexes & \\
$\%$ of overlap & (Total overlap/Total frequency of turn) $\times 100$ \\
$\%$ of turn interruption & (Total interruption/Total frequency of turn) $\times 100$ \\
\hline
\end{tabular}

는 석사과정생이다. 제 1 분석자 및 제 2 분석자는 본 연구에서 사용 한 프로토콜의 저자 중 1 명에게 대화 절차 및 분석방법에 대해 충 분한 훈련을 받은 뒤, 분석 신뢰도가 $90 \%$ 이상이 되었을 때 수집된 자료 중 $20 \%$ 를 무작위로 추출하여 분석하였다. 일치율은 '대화참 여지표', '주제운용지표' '대화방해지표' 세 가지 측면으로 나누어 두 검사자 간의 일치한 반응수를 일치하지 않은 반응수와 일치한 반응수로 합하여 나눈 뒤 100 을 곱하여 산출하였다. 그 결과, 대화 참여지표 $97.17 \%$, 주제운용지표 $96.83 \%$, 대화방해지표 $98.08 \%$ 로 측정되었다.

\section{자료의 통계처리}

자료의 통계처리는 Statistical Package for the Social Sciences (SPSS version 22; IBM, Armonk, NY, USA)를 사용하였으며 두 집 단 간 대화참여지표(대화차례빈도, 대화차례당 발화수), 주제운용 지표(전체주제수, 주제당 대화차례빈도, 전체주제개시율, 전체주제 유지율, 전체주제변경률), 대화방해지표(대화중단율, 대화중첩률) 측면에서의 수행력 차이를 비교하기 위해 먼저 Kolmogorov-Smirnov와 Shapiro-Wilk 검증법을 이용하여 정규분포 검정을 실시한 결과, 일부 측정치에서 정규분포 가정이 불충족되었다. 이에 본 연 구의 표본수 등을 함께 고려하여 모든 측정치에 대해 비모수 검정 방법인 맨휘트니 $U$-검정(Mann-Whitney $U$-test)을 실시하였다.

\section{연구결과}

\section{두 집단 간 대화참여지표 수행 차이}

통계분석 결과, 대화차례빈도 $(U=46.5, p=.143)$ 와 대화차례당 발화수 $(U=65.0, p=.713)$ 에서 유의미한 차이는 나타나지 않았다.
Table 3. Result of Mann-Whitney Utest in conversational participation indexes

\begin{tabular}{lccrc}
\hline & $\mathrm{M} \pm \mathrm{SD}$ & Median (IOR) & $U$ & $p$-value \\
\hline Number of turn-taking & & & 46.5 & .143 \\
NA group ( $\mathrm{N}=12)$ & $59.08 \pm 16.77$ & $60.50(43.50-64.00)$ & & \\
RHD group ( $\mathrm{N}=12)$ & $47.92 \pm 16.17$ & $44.50(32.75-61.00)$ & & \\
Frequency of utterances per turn & & 65 & .713 \\
NA group ( $\mathrm{N}=12)$ & $1.95 \pm 0.39$ & $2.11(1.62-2.21)$ & & \\
RHD group ( $\mathrm{N}=12)$ & $2.62 \pm 2.2$ & $1.90(1.41-3.32)$ & & \\
\hline
\end{tabular}

$\mathrm{NA}=$ normal adults; $\mathrm{RHD}=$ right hemisphere damage; $\mathrm{IQR}=$ interquartile range (0103).

대화참여지표에 대한 통계분석 결과는 Table 3과 같다.

\section{두 집단 간 주제운용지표 수행 차이}

통계분석 결과, 전체주제수 $(U=18.00, p=.001)$, 주제당 대화차례 빈도 $(U=22.00, p=.003)$, 전체주제개시율 $(U=37.50, p=.045)$, 전체 주제유지율 $(U=15.00, p=.000)$, 전체주제변경률 $(U=8.00, p=.000)$ 에서 모두 유의미한 차이를 보였다. '전체주제수'는 RHD가 NA보 다 더 높이 나타났고, ‘주제당 대화차례빈도'에서는 RHD가 NA보 다 더 낮게 나타났다. '주제개시율'과 '주제변경률'에서는 RHD가 NA보다 더 높게 나타났으며 '주제유지율'에서는 RHD가 NA보다 더 낮게 나타났다. 주제운용지표에 대한 통계분석 결과는 Table 4 와같다.

\section{두 집단 간 대화방해지표 수행 차이}

통계분석 결과, 대화중첩률 $(U=38.00, p=.052)$ 과 대화중단율 $(U=48.50, p=.178)$ 에서 유의미한 차이는 나타나지 않았다. 대화 방해지표에 대한 통계분석 결과는 Table 5와 같다. 
Table 4. Result of Mann-Whitney U test in topic manipulation indexes

\begin{tabular}{lrlrl}
\hline & $\mathrm{M} \pm \mathrm{SD}$ & Median (IOR) & $U$ & $p$-value \\
\hline Total number of topics & & & 18 & $.001^{* *}$ \\
NA group ( $\mathrm{N}=12)$ & $12.92 \pm 1.56$ & $13.00(11.25-14.75)$ & \\
RHD group ( $\mathrm{N}=12)$ & $19.67 \pm 9.03$ & $17.00(14.25-20.75)$ & \\
Frequency of turns per topic & & & 22 & $.003^{* *}$ \\
NA group ( $\mathrm{N}=12)$ & $4.6 \pm 1.65$ & $4.49(3.12-5.40)$ & & \\
RHD group ( $\mathrm{N}=12)$ & $2.72 \pm 1.18$ & $2.56(1.94-3.63)$ & & \\
\% of topic initiation & & & 37.5 & $.045^{*}$ \\
NA group ( $\mathrm{N}=12)$ & $3.46 \pm 0.85$ & $3.22(3.05-4.06)$ & & \\
RHD group ( $\mathrm{N}=12)$ & $4.8 \pm 1.62$ & $4.83(3.29-6.25)$ & & \\
\% of topic maintenance & & & 15 & $.000^{* * *}$ \\
NA group ( $\mathrm{N}=12)$ & $92.51 \pm 3.34$ & $92.26(90.49-95.25)$ & & \\
RHD group ( $\mathrm{N}=12)$ & $82.03 \pm 8.88$ & $85.61(72.38-88.69)$ & & \\
\% of topic switching & & & 8 & $.000^{* * *}$ \\
NA group ( $\mathrm{N}=12)$ & $2.92 \pm 2.84$ & $2.02(0.39-5.44)$ & & \\
RHD group ( $\mathrm{N}=12)$ & $13.13 \pm 7.88$ & $9.28(7.30-21.24)$ & & \\
\hline
\end{tabular}

$\mathrm{NA}=$ normal adults; $\mathrm{RHD}=$ right hemisphere damage; $\mathrm{IQR}=$ interquartile range $(\mathrm{Q} 1$ Q3).

${ }^{*} p<.05,{ }^{* *} p<.01,{ }^{* * *} p<.001$.

\section{논의 및 결론}

본 연구에서는 50-80대 RHD 집단의 대화 특성을 '대화참여지 표' '대화주제운용지표', '대화방해지표'의 세 가지 측면으로 나누 어 정상성인 집단과 비교하였다. 먼저 대화차례빈도와 대화차례당 발화수로 살펴본 '대화참여지표'에 따른 수행력에서는 집단 간 유 의미한 차이를 보이지 않았다. 이는 RHD 환자가 정상인보다 지나 치게 발화량이 많거나(Prutting \& Kirchner, 1987), 대화 주고받기 의 빈도는 더 많지만 대화차례당 발화수는 오히려 더 적었다는 국 외의 선행연구(Kennedy et al., 1994)와는 다른 연구결과이다. 본 연 구결과뿐만 아니라 선행연구들 내에서도 서로 다른 연구결과를 보 인 이유는 대화 과제 자체가 가지는 특성 때문일 수 있다. 대화는 특 정 맥락이 주어지고 그 맥락에 따라 자신의 생각이나 감정 등을 표 현하며 상호작용하는 것으로, 대화의 주제에 따라 발화의 양이 증 가되거나 감소할 수 있는 특성을 지닌다. 실제적으로 본 연구의 대 화 내용을 질적으로 살펴보면 일부 대상자는 대화에 더 참여하여 대화량이 증가하기도 하였고, 또 다른 대상자는 그 양이 감소되기 도 하였다. 이는 대상자에 따라 더 감소된 대화를 보이거나 정상적 인 수준의 대화를 보이기도 하므로(Brookshire, 2014) 대화참여의 정도만으로는 RHD 집단의 특성을 대변하기 어렵다는 보고(Prutting \& Kirchner, 1987)가 이를 뒷받침한다.

또한 그간 대화 과제를 사용하여 RHD의 대화참여 정도를 살펴 보는 국내의 선행연구는 없었으므로 직접적인 비교는 어려우나, 이
Table 5. Result of Mann-Whitney U test in conversational breakdown

\begin{tabular}{lcccc}
\hline & $\mathrm{M} \pm \mathrm{SD}$ & Median (IOR) & $U$ & $p$-value \\
\hline \% of overlap & & & 38 & .052 \\
NA group ( $\mathrm{N}=12)$ & $0.39 \pm 0.97$ & $0(0-0)$ & & \\
RHD group ( $\mathrm{N}=12)$ & $3.23 \pm 3.65$ & $1.72(0-6.36)$ & & \\
\% of turn interruption & & & 48.5 & .178 \\
NA group ( $\mathrm{N}=12)$ & $0.31 \pm 1.08$ & $0(0-0)$ & & \\
RHD group (N=12) & $1.55 \pm 2.35$ & $0(0-2.92)$ & & \\
\hline
\end{tabular}

$\mathrm{NA}=$ normal adults; $\mathrm{RHD}=$ right hemisphere damage; $\mathrm{IQR}=$ interquartile range $(01-$ 03).

야기나 설명하기 담화 과제를 사용한 연구를 통해 발화량이 감소 하는 것이 보고되었다. 흥부와 놀부 이야기 산출을 통해 담화의 양 적인 측면과 질적인 측면을 살펴본 연구(Baik, 2004)에서는 담화의 전체 발화의 양은 정상성인에 비해 감소하는 결과를 보였고, 'cookie theft' 그림을 이용하여 그림 설명하기 방법을 통해 알츠하이머 치매군과 우반구 손상 환자군의 담화를 비교한 연구(Sohn et al., 2007)에서도 RHD 집단이 정상성인 집단에 비해 더 적은 발화량 을 보였다. 이러한 차이는 과제 유도 방식의 특성에 기인하였을 수 있는데 본 연구는 대화 상대자와 서로 주고받는 방식을 사용하였 기 때문에 대화 맥락 내에서 보다 자연스럽고 기능적인 발화를 이 끌어 RHD 환자의 대화 특성을 보다 더 잘 드러낸 반면, 상기 연구 는 대상자의 일방적인 발화산출 과제를 유도하였기 때문에 맥락에 따라 발화를 산출한 것이 아니므로 본 연구결과와 같지 않을 수 있 다. 또한 본 연구에서 사용된 대화 프로토콜은 절차에 따라 대화가 진행되나 대화 시 일정한 시간적 제한을 두고 있지 않으므로 대화 의 참여에 대한 해석이 다소 제한될 수 있다. 따라서 이러한 점들을 고려하였을 때, $\mathrm{RHD}$ 의 대화참여 특성을 살펴보기 위해서는 일정 한 대화의 시간을 동일하게 통제하여 살펴보는 것이 필요하며, 환 자의 발병 전 대화참여 특성을 파악하여 발병 후와 비교하는 과정 도 필요함을 보여준다.

'대화참여지표'에서 집단 간 유의미한 차이가 없던 것에 비하여 ‘주제운용지표’에 따른 수행력을 살펴보면 RHD 집단은 NA 집단 보다 더 낮은 주제유지율을 보였으나 주제변경률과 개시율은 더 높 게 나타났다. RHD 환자들의 발화를 더 세부적으로 살펴본 결과, 한 주제를 가지고 대화할 때 자신의 대화차례 내에서도 빈번하게 주제를 변경하면서 발화를 산출하는 양상을 보였다. 화자가 본인 의 대화차례 내에서 주제를 유지하기 위해서는 직전 발화와 다음 에 제시될 발화의 맥락을 유지시켜야 하는데 본 RHD 환자들은 대 화 시 빈번하게 새로운 내용을 제시하였다. 빈번한 개시나 변경은 청자의 입장에서 맥락에 맞지 않는 발화로 느껴질 수 있고 대화의 흐름에 대한 이해를 어렵게 한다. 따라서 이러한 결과는 RHD 집단 
이 주제를 유지하기 어렵고 의사소통 상황에서 부적절한 말을 하 고 청자의 입장을 고려하지 못한다는 선행연구를 뒷받침하는 결과 (Rehak et al., 1992; Tompkins \& Flowers, 1985)라 할 수 있겠다.

우반구 손상 환자가 보일 수 있는 의사소통 문제는 인지적 손상 이 원인이 될 수 있다는 근거하에(Blake, 2005; Park \& Kim, 2012) 본 RHD 환자들의 병소를 검토해 보았다. 대상자 12 명 중 3 명은 전 두엽에 병변이 있었으며, 6명은 전두-피질하 회로(frontal-subcortical circuit)에 영향을 주는 피질하구조에 병변이 있었다. 따라서 우 반구 전두엽기능 부전에 좀 더 초점을 맞추어 본 연구결과를 해석 해 보고자 한다. 먼저, 전두엽은 다양한 인지기능의 근간이 되지만 특히 우반구 전두엽은 부적절한 반응을 중단하는 능력(Banich \& Compton, 2014)인 '억제능력'과 관련이 있는 것으로 알려져 있다. 이는 우반구 중전두피질, 우반구 하전두피질, 전 보조영역과 두정 엽을 포함하는 우반구 네트워크에 의해 통제되며(Aron, Fletcher, Bullmore, Sahakian, \& Robbins, 2003; Banich \& Compton, 2014; Li, Huang, Constable, \& Sinha, 2006; Liddle, Kiehl, \& Smith, 2001; Nee, Wager, \& Jonides, 2007) 우반구의 손상 정도에 따라 억제능력 이 예측될 수 있다(Aron et al., 2003). 따라서 RHD 집단은 제한된 억제능력으로 인해 대화 맥락과 관련 없이 계속 새로운 주제를 개 시하거나 변경하는 대화 양상을 보였을 수 있다. 또한 대화의 주제 를 적절하게 유지하기 위해서는 대화에서 다루어지고 있는 주제가 무엇인지 파악하고 전 발화에 대한 내용과 맥락을 기억하는 상태 에서 그 맥락에 맞는 발화를 산출하여야 한다. 이러한 동시적 정보 처리 과정은 담화 내의 내용을 임시로 저장하고 통합하는 기억 체 계인 작업기억에 기반한다(Baddeley, 1993) 작업기억은 RHD 환자 의 화용언어 및 담화와 같은 의사소통 문제와 깊은 관계가 있음이 보고되었다(Martin \& McDonald, 2003; Park \& Kim, 2012; Shin \& Choi, 2017). 이와 관련하여 우반구의 중전두피질과 하전두피질은 작업기억의 처리 과정을 담당하며(Wager \& Smith, 2003), RHD 환 자들이 언어적 정보를 저장하고 통합하는 과제에서 수행력이 저하 되었다는 결과(Blasko, 1999; Kazmerski, Blasko, \& Dessalegn, 2003; Park \& Kim, 2012; Shin \& Choi, 2017; Tompkins, Boada, \& McGarry, 1992)를 통해 본 연구결과를 뒷받침할 수 있다. 또 다른 관점으로는 우반구 손상으로 인하여 양반구의 통합 처리에 기반 하는 정보처리 효율성이 저하되었을 가능성이 있다. 각 반구는 특 정 기능에 대하여 편재화되어 있지만 뇌량으로 연결되어 각 뇌영역 에 들어온 정보들을 교환하고 통합함으로써 정보를 효율적으로 처 리한다. 그러므로 각각의 반구가 분명하게 다른 정보처리를 하도록 특성화되어 있다고 할지라도 산출되는 결과물은 통합된 대뇌 처리 과정을 반영하는 것이라 할 수 있다(Banich \& Compton, 2014). 뇌
는 과제를 수행할 시 과제의 난이도에 따라 반구 간 시행(acrosshemisphere trials)과 반구 내 시행(within-hemisphere trials) 방법 을 통해 정보를 처리할 수 있는데(Banich \& Compton, 2014) 과제 의 난이도가 낮은 경우에는 상대적으로 각 뇌반구 내에서 담당하 여 처리하면 보다 효율성 있게 처리할 수 있고, 난이도가 높은 과제 의 경우에는 양반구 전반에 걸쳐 정보들을 함께 처리하는 것이 보 다 효율적일 수 있다(Banich \& Belger, 1990; Banich \& Brown, 2000; Banich, Passarotti, \& Janes, 2000; Belger \& Banich, 1992, 1998; Reuter-Lorenz, Stanczak, \& Miller, 1999). 이러한 관점에서 대화의 주제운용에는 다양한 의미적, 담화적, 화용적 처리 과정이 수반되 므로 단순 이해나 산출 과제보다 과제의 난이도가 높을 수 있다. 따 라서 대화처리 및 주제운용을 위하여 양반구의 기능이 통합적으 로 활성화되어야 하므로 본 RHD 환자는 양반구가 함께 처리해야 하는 과제를 좌반구에서 보다 편중하여 처리하게 되면서 정보 처리 의 효율성이 저하되어 주제운용능력이 저하되는 결과를 보였을 수 있겠다.

'대화방해지표'의 중단과 중첩 모두에서는 집단 간 유의미한 차 이가 없었다. 이는 RHD 환자가 청자를 고려하지 못하고 대화를 갑 자기 시작하거나 끝내기도 한다는 연구(Diggs \& Basili, 1987; Jang \& Choi, 2010; Rehak et al., 1992; Tompkins \& Flowers, 1985)와 대 화 시 대화를 조절하는 능력이 저하되어 대화 순서를 지키거나 적 절한 대화를 유지하는 데 어려움을 보인다는 결과(Lee \& Kim, 2011) 와 일치하지 않는 결과이다. 그러나 비록 유의미한 차이는 나타나 지 않았으나, 대화중첩률에서는 NA 집단보다 RHD 집단이 더 높 은 수치를 보였다. 대화중첩을 하지 않기 위해서는 상대방의 대화 차례가 끝날 때까지 기다릴 수 있어야 하는데, RHD 환자는 상대방 의 대화차례가 끝날 때까지 기다리지 못하고 자기 대화차례를 시작 하므로 대화중첩 현상이 빈번하게 발생한 것일 수 있다. 이와 더불 어 통계적으로 유의하지는 않지만 RHD 환자가 중첩이 많았던 결 과는 우반구의 주요기능에 해당되는 운율 처리능력의 결함에 기인 한 것일 수 있다. 일반적으로 운율은 언어의 해석에 대한 정보를 제 공하며, 어떠한 억양을 사용하느냐에 따라 전달하고자 하는 내용 을 더욱 명료하게 할 뿐만 아니라 상황에 따른 맥락이나 정서적인 이해를 가능하게 하므로 화용 언어와 밀접하게 관련되어 있다 $(\mathrm{Lim}$ \&Yoo, 2015). 대화에서도 운율 및 억양은 대화의 시작과 끝을 암시 하므로 대화의 순서와 차례를 더 잘 파악할 수 있게 한다. 그러나 $\mathrm{RHD}$ 환자는 운율적인 정보를 이해하는 데 어려움이 있으며 단조 로운 억양을 사용하는 등 비언어적인 정보를 활용하는 것에서 결 함을 보이기 때문에(Jang \& Choi, 2010; Lim \& Yoo, 2015) 대화 시 상대방의 발화 개시나 종결 여부를 명확하게 이해하지 못하여 대 
화의 중첩이 빈번히 관찰된 것으로 해석할 수 있다.

본 연구의 결과를 종합해 보면, 대화의 주제 개시, 유지, 변경과 같은 대화주제를 다루는 주제운용지표에서 집단 간 유의한 차이 를 보였다. 이는 우반구 손상 환자가 새로운 주제를 개시하거나 변 경하는 빈도가 높아 정상 성인 집단보다 공통된 주제로 대화를 유 지하는 능력이 저하된다는 것을 보여준다. 따라서 대화의 주제운 용지표를 통하여 우반구 손상 환자가 보일 수 있는 의사소통적 결 함을 확인할 수 있음을 의미한다. 추가적으로 대화중첩 및 중단율 과 같은 대화방해지표에서는 통계적으로 유의한 차이가 없었으나 집단 간 평균을 살펴보았을 때, 대화중첩률의 경우 그 차이가 크게 나타나므로 추후 대단위 연구를 통해 대화 방해 특성에 대한 후속 연구가 필요함을 의미한다.

임상적으로 RHD 환자는 화용적 측면에서 의사소통의 어려움 을 호소하나 좌반구 기능 중심의 언어 평가상에서 선별되지 않아, 실제로는 의사소통 중재가 필요할 수 있음에도 불구하고 중재로 이어질 수 있는 근거가 미약하였다. 그러나 본 연구결과를 통해 $\mathrm{RHD}$ 환자가 가진 대화와 주제운용능력에 대한 특성을 확인함으 로써 이와 같은 결함에 기반한 환자의 평가 및 중재의 기초 근거를 제공하였다는 것에 연구의 의의가 있다. 본 연구의 제한점으로는 첫째, 연구결과의 수치상 NA 집단보다 RHD 환자에서 표준편차가 크게 나타났다. 이는 본 연구에서 연구대상자의 뇌혈관장애의 종 류나 발병 후 경과일수는 통제하였으나 병변을 통제하지 않았으므 로 이러한 다양성이 환자군의 표준편차에 영향을 주었을 가능성 이 있다. 둘째, RHD 환자의 대상자 수가 충분치 않으므로 추후 대 단위 연구를 통해 RHD의 대화 특성을 일반화하고 확립하는 과정 이 필요하겠다. 셋째, 본 연구에서는 RHD 환자의 종합인지기능검 사를 통하여 하위 인지기능을 세부적으로 확인하지 못하였으므로 인지기능과 대화 특성 간의 직접적인 관련성을 확인할 수 없다. 이 에 본 결과의 해석 시 주의가 필요하며 추후 신경심리학적 검사결 과를 포함한 연구를 통해 우반구 관련 인지기능과 대화기능 간의 관계를 살펴보는 연구가 필요하겠다. 마지막으로 병변의 위치에 따 른 뇌영상 분석을 통하여 병소와 각 지표와의 관련성을 확인한다 면 대화능력 평가를 통해 뇌손상 여부나 손상된 병변을 예측하여 진단할 수 있는 감별적 정보를 제공할 수 있을 것이다.

\section{REFERENCES}

Adams, C., \& Bishop, D. V. (1989). Conversational characteristics of children with semantic-pragmatic disorder. I. Exchange structure, turntaking, repairs and cohesion. International Journal of Language \& Communication
Disorders, 24(3), 211-239.

Ahn, J. B. (2008). Study on Korean Proverb comprehension in patients with right hemisphere damage. Speech Sciences, 15(3), 67-78.

Ahn, J. B. (2011). A study of the expressive ability of Korean proverbs by individuals with right hemisphere damage. Journal of Speech-Language and Hearing Disorders, 20(1), 173-190.

Anderson, T. P., Bourestom, N., Greenberg, F. R., \& Hildyard, V. G. (1974). Predictive factors in stroke rehabilitation. Archives of Physical Medicine and Rehabilitation, 55(12), 545-553.

Aron, A. R., Fletcher, P. C., Bullmore, E. T., Sahakian, B. J., \& Robbins, T. W. (2003). Stop-signal inhibition disrupted by damage to right inferior frontal gyrus in humans. Nature Neuroscience, 6(2), 115-116.

Baddeley, A. (1993). Working memory and conscious awareness. In A. F. Collins et al. (Eds.), Theories of memory (pp. 11-28). Hove, UK: Lawrence Erlbaum Associates.

Baik, K. S. (2004). Analyses of semantic contents and organization of narratives in right brain damaged patients. Korean Journal of Communication Disorders, 9(3), 72-101.

Banich, M. T., \& Belger, A. (1990). Interhemispheric interaction: how do the hemispheres divide and conquer a task? Cortex, 26(1), 77-94.

Banich, M. T., \& Brown, W. S. (2000). A life-span perspective on interaction between the cerebral hemispheres. Developmental Neuropsychology, 18(1), $1-10$.

Banich, M. T., \& Compton, R. J. (2014). Cognitive neuroscience (3rd ed., M. S. Kim et al. Trans.). Seoul: Pakhaksa.

Banich, M. T., Passarotti, A. M., \& Janes, D. (2000). Interhemispheric interaction during childhood. I. Neurologically intact children. Developmental Neuropsychology, 18(1), 33-51.

Bartels-Tobin, L. R., \& Hinckley, J. J. (2005). Cognition and discourse production in right hemisphere disorder. Journal of Neurolinguistics, 18(6), 461-477.

Belger, A., \& Banich, M. T. (1992). Interhemispheric interaction affected by computational complexity. Neuropsychologia, 30(10), 923-929.

Belger, A., \& Banich, M. T. (1998). Costs and benefits of integrating information between the cerebral hemispheres: a computational perspective. Neuropsychology, 12(3), 380-398.

Bishop, D. V., Chan, J., Adams, C., Hartley, J., \& Weir, F. (2000). Conversational responsiveness in specific language impairment: evidence of disproportionate pragmatic difficulties in a subset of children. Development and Psychopathology, 12(2), 177-199. 
Blake, M. L. (2005). Right hemisphere syndrome. In L. L. LaPointe (Ed.), Aphasia and related neurogenic language disorders (3rd ed., pp. 213-224). New York, NY: Thieme.

Blasko, D. G. (1999). Only the tip of the iceberg: who understands what about metaphor? Journal of Pragmatics, 31(12), 1675-1683.

Brady, M., Mackenzie, C., \& Armstrong, L. (2003). Topic use following right hemisphere brain damage during three semi-structured conversational discourse samples. Aphasiology, 17(9), 881-904.

Brinton, B., \& Fujiki, M. (1984). Development of topic manipulation skills in discourse. Journal of Speech, Language, and Hearing Research, 27(3), 350358.

Brinton, B., Fujiki, M., \& Powell, J. M. (1997). The ability of children with language impairment to manipulate topic in a structured task. Language, Speech, and Hearing Services in Schools, 28(1), 3-11.

Brookshire, R. H. (2014). Introduction to neurogenic communication disorders (7th ed., M. Kwon et al., Trans.). Seoul: Pakhaksa.

Bryan, K. L., \& Hale, J. B. (2001). Differential effects of left and right cerebral vascular accidents on language competency. Journal of the International Neuropsychological Society, 7(6), 655-664.

Bryan, T., Donahue, M., Pearl, R., \& Sturm, C. (1981). Learning disabled children's conversational skills: the 'TV Talk Show'. Learning Disability Quarterly, 4(3), 250-259.

Chantraine, Y., Joanette, Y., \& Ska, B. (1998). Conversational abilities in patients with right hemisphere damage. Journal of Neurolinguistics, 11(1-2), 21-32.

Cherney, L. R., \& Halper, A. S. (2001). Unilateral visual neglect in right-hemisphere stroke: a longitudinal study. Brain Injury, 15(7), 585-592.

Choi, J., \& Lee, Y. (2013). Conversational turn-taking and topic manipulation skills of children with high-functioning autism spectrum disorders. Communication Sciences \& Disorders, 18(1), 12-23.

Choi, J., \& Lee, Y. (2015). Contingency and informativeness of topic maintenance in children with high-functioning autism spectrum disorders. Communication Sciences \& Disorders, 20(3), 413-423.

Christensen, K. J., Multhaup, K. S., Nordstrom, S., \& Voss, K. (1991). A cognitive battery for dementia: development and measurement characteristics. Psychological Assessment: A Journal of Consulting and Clinical Psychology, 3(2), 168-174.

Coq, J. O., \& Xerri, C. (1999). Acute reorganization of the forepaw representation in the rat SI cortex after focal cortical injury: neuroprotective effects of piracetam treatment. European Journal of Neuroscience, 11(8), 2597-2608.
Craig, H. K., \& Evans, J. L. (1989). Turn exchange characteristics of SLI children's simultaneous and nonsimultaneous speech. Journal of Speech and Hearing Disorders, 54(3), 334-347.

Crystal, D., Fletcher, P., \& Garman, M. (1976). The grammatical analysis of language disability: a procedure for assessment and remediation. London: Edward Arnold.

Diggs, C. C., \& Basili, A. G. (1987). Verbal expression of right cerebrovascular accident patients: convergent and divergent language. Brain and Language, 30(1), 130-146.

Evans, J. L., \& Craig, H. K. (1992). Language sample collection and analysis: Interview compared to freeplay assessment contexts. Journal of Speech, Language, and Hearing Research, 35(2), 343-353.

Heo, H., \& Lee, Y. K. (2012). Conversational turn-taking and topic manipulation skills in conversations of school-age low-achievers in language learning. Korean Journal of Communication \& Disorders, 17(1), 66-78.

Hird, K., \& Kirsner, K. (2003). The effect of right cerebral hemisphere damage on collaborative planning in conversation: an analysis of intentional structure. Clinical Linguistics \& Phonetics, 17(4-5), 309-315.

Hong, U., \& Lee, Y. (2016). Conversational characteristics of children with a mild intellectual disability. Special Education Research, 15(2), 111-126.

Jang, H. S., \& Choi, H. (2010). Comprehension of indirect speech acts in patients with right brain damage. Korean Journal of Communication \& Disorders, 15(4), 581-591.

Jauch, E. C., Saver, J. L., Adams Jr, H. P., Bruno, A., Connors, J. J., Demaerschalk, B. M., ... \& Scott, P. A. (2013). Guidelines for the early management of patients with acute ischemic stroke: a guideline for healthcare professionals from the American Heart Association/American Stroke Association. Stroke, 44(3), 870-947.

Joanette, Y., Goulet, P., Ska, B., \& Nespoulous, J. L. (1986). Informative content of narrative discourse in right-brain-damaged right-handers. Brain and Language, 29(1), 81-105.

Jorgensen, H. S., Nakayama, H., Reith, J., Raaschou, H. O., \& Olsen, T. S. (1996). Factors delaying hospital admission in acute stroke: the Copenhagen Stroke Study. Neurology, 47(2), 383-387.

Kang, Y. (2006). A normative study of the Korean-Mini Mental State Examination (K-MMSE) in the elderly. Korean Journal of Psychology: General, 25(2), 1-12.

Kaplan, J. A., Brownell, H. H., Jacobs, J. R., \& Gardner, H. (1990). The effects of right hemisphere damage on the pragmatic interpretation of conversational remarks. Brain and Language, 38(2), 315-333. 
Kazmerski, V. A., Blasko, D. G., \& Dessalegn, B. G. (2003). ERP and behavioral evidence of individual differences in metaphor comprehension. Memory \& Cognition, 31(5), 673-689.

Kee, B. S. (1996). A preliminary study for the standardization of geriatric depression scale short form-Korea version. Journal of the Korean Neuropsychiatric Association, 35(2), 298-307.

Kennedy, M. R. (2000). Topic scenes in conversations with adults with righthemisphere brain damage. American Journal of Speech-Language Patholo$g y, 9(1), 72-86$.

Kennedy, M. R., Strand, E. A., Burton, W., \& Peterson, C. (1994). Analysis of first-encounter conversations of right-hemisphere-damaged adults. Clinical Aphasiology, 22, 67-80.

Kertoy, M. K., \& Vetter, D. K. (1995). The effect of conversational setting on topic continuation in mother-child dyads. Journal of Child Language, 22(1), 73-88.

Kim, E. J., \& Choi, Y. (2009). Metaphor comprehension with a damaged right hemisphere: focusing on word association and verbal analogical processes. Korean Journal of Communication Disorders, 14(1), 70-81.

Kim, H., Heo, J. H., Kim, D. Y., \& Kim, J. W. (2009). Screening test for aphasia and neurologic-communication disorders (STAND). Seoul: Hakjisa.

Kim, S. E., \& Lee, Y. (2007). Conversation characteristics of children with attention deficit hyperactivity disorder. Korean Journal of Communication Disorders, 12(4), 662-675.

Kim, Y. T. (1997). Study of MLU in Korean 2-4 years children. Korean Journal of Communication Disorders, 2, 5-25.

Lee, H. J., \& Kim, Y. T. (2001). Turn-taking characteristics of children with specific language impairment and normal children. Korean Journal of Communication \& Disorders, 6(2), 293-312.

Lee, J. H., Kim, K. S., \& Ahn, J. B. (2015). A study on simile comprehension in adult with brain damage. Journal of Speech-Language \& Hearing Disorders, 24(4), 159-170.

Lee, M. S., \& Kim, H. H. (2011). Assessment tools of cognitive-communicative ability for traumatic brain injury and right hemisphere damage: a review. The Journal of the Korea Contents Association, 11(4), 253-262.

Lee, S. H., Lim, J., \& Hwang, M. (2009). Metaphor comprehension in adults with right-hemisphere brain damage: some effects of task presentation conditions. Korean Journal of Communication Disorders, 14(4), 484-494.

Lee, Y., \& Lee, H. J. (2013). Conversational turn-taking of toddlers with language delay. Special Education Research, 12(3), 357-377.

Li, C. S. R., Huang, C., Constable, R. T., \& Sinha, R. (2006). Imaging response inhibition in a stop-signal task: neural correlates independent of signal monitoring and post-response processing. Journal of Neuroscience, 26(1), 186-192.

Liddle, P. F., Kiehl, K. A., \& Smith, A. M. (2001). Event-related fMRI study of response inhibition. Human Brain Mapping, 12(2), 100-109.

Lim, H. S., \& Yoo, J. Y. (2015). The intonation characteristics of reading sentences in patients with right hemisphere damage. Journal of Speech-Language \& Hearing Disorders, 24(4), 183-191.

Lund, N. J., \& Duchan, J. F. (1993). Assessing children's language in naturalistic contexts (3rd ed.). Englewood Cliffs, NJ: Prentice Hall.

Marini, A. (2012). Characteristics of narrative discourse processing after damage to the right hemisphere. Seminars in Speech and Language, 33(1), 6878.

Marini, A., Carlomagno, S., Caltagirone, C., \& Nocentini, U. (2005). The role played by the right hemisphere in the organization of complex textual structures. Brain and Language, 93(1), 46-54.

Marotta, J. J., McKeeff, T. J., \& Behrmann, M. (2003). Hemispatial neglect: its effects on visual perception and visually guided grasping. Neuropsychologia, 41(9), 1262-1271.

Martin, I., \& McDonald, S. (2003). Weak coherence, no theory of mind, or executive dysfunction? Solving the puzzle of pragmatic language disorders. Brain and Language, 85(3), 451-466.

Mentis, M. (1994). Topic management in discourse: assessment and intervention. Topics in Language Disorders, 14(3), 29-54.

Min, J. S., Yoon, J. H., Na, D. L., \& Lee, Y. (2018). Characteristics of conversation in frontotemporal dementia: comparison with dementia of the Alzheimer's type. Communication Sciences \& Disorders, 23(1), 146-159.

Nee, D. E., Wager, T. D., \& Jonides, J. (2007). Interference resolution: insights from a meta-analysis of neuroimaging tasks. Cognitive, Affective, \& Behavioral Neuroscience, 7(1), 1-17.

Oldfield, R. C. (1971). The assessment and analysis of handedness: the Edinburgh inventory. Neuropsychologia, 9(1), 97-113.

Owens, R. E. (2004). Language disorders: a functional approach to assessment and intervention (4th ed.). Boston, MA: Allyn \& Bacon.

Owens, R. E. (2010). Language disorders: a functional approach to assessment and intervention (5th ed.). Boston, MA: Allyn \& Bacon.

Park, W. K., \& Kim, K. (2012). Declined working memory in patients with right cerebral hemispheric lesions. Korean Journal of Clinical Geriatrics, 13(2), 186-193.

Park, Y. J., Choi, J., \& Lee, Y. (2017). Development of topic management skills 
in conversation of school-aged children. Communication Sciences \& Disorders, 22(1), 25-34.

Prutting, C. A., \& Kittchner, D. M. (1987). A clinical appraisal of the pragmatic aspects of language. Journal of Speech and Hearing Disorders, 52(2), 105119.

Rehak, A., Kaplan, J. A., \& Gardner, H. (1992). Sensitivity to conversational deviance in right-hemisphere-damaged patients. Brain and Language, 42(2), 203-217.

Reuter-Lorenz, P. A., Stanczak, L., \& Miller, A. C. (1999). Neural recruitment and cognitive aging: two hemispheres are better than one, especially as you age. Psychological Science, 10(6), 494-500.

Schober-Peterson, D., \& Johnson, C. J. (1989). Conversational topics of 4-yearolds. Journal of Speech, Language, and Hearing Research, 32(4), 857-870.

Schober-Peterson, D., \& Johnson, C. J. (1993). The performance of eight-to ten-year-olds on measures of conversational skilfulness. First Language, 13(38), 249-269.

Seong, S. Y., \& Kim, Y. (2015). Characteristics of informativeness, efficiency and use of conjunction markers in spontaneous utterances of the right hemisphere damaged adults. Journal of Rehabilitation Research, 19(2), 315338.

Shapiro, B. E., \& Danly, M. (1985). The role of the right hemisphere in the control of speech prosody in propositional and affective contexts. Brain and Language, 25(1), 19-36.

Shin, H. D., \& Choi, S. (2017). The relationship between working memory and metaphor comprehension in patients with right hemisphere damage. Communication Sciences \& Disorders, 22(4), 745-755.

Sohn, E. N., Kim, H. J., \& Park, S. H. (2007). Discourse analyses by Alzheim- er' disease and right hemisphere damaged use analyze method main concept. Journal of Special Education \& Rehabilitation Science, 46(4), 255-269.

Tompkins, C. A. (2012). Rehabilitation for cognitive-communication disorders in right hemisphere brain damage. Archives of Physical Medicine and Rehabilitation, 93(1), S61-S69.

Tompkins, C. A., Boada, R., \& McGarry, K. (1992). The access and processing of familiar idioms by brain-damaged and normally aging adults. Journal of Speech, Language, and Hearing Research, 35(3), 626-637.

Tompkins, C. A., \& Flowers, C. R. (1985). Perception of emotional intonation by brain-damaged adults: the influence of task processing levels. Journal of Speech, Language, and Hearing Research, 28(4), 527-538.

Wager, T. D., \& Smith, E. E. (2003). Neuroimaging studies of working memory. Cognitive, Affective, \& Behavioral Neuroscience, 3(4), 255-274.

Weiner, S. L., \& Goodenough, D. R. (1977). A move toward a psychology of conversation. Discourse Production and Comprehension, 1, 213-224.

Woo, H. R., \& Kim, J. (2017). The study trends of the right hemisphere damage cognitive-communication disorders. Journal of Rehabilitation Research, 21(1), 213-231.

Yang, Y., Lee, Y., Choi, J., \& Yoon, J. (2018). Development of conversational skills from late children to adolescent. Communication Sciences \& Disorders, 23(2), 270-278.

Yorkston, K. M., \& Beukelman, D. R. (1980). An analysis of connected speech samples of aphasic and normal speakers. Journal of Speech and Hearing Disorders, 45(1), 27-36.

Zaidel, E., Kasher, A., Soroker, N., \& Batori, G. (2002). Effects of right and left hemisphere damage on performance of the "Right Hemisphere Communication Battery". Brain and Language, 80(3), 510-535. 
Appendix 1. 우반구 손상 환자 정보

\begin{tabular}{|c|c|c|c|}
\hline Gender & Age (yr) & РОТ (day) & Lesion \\
\hline M & 55 & 1 & $\begin{array}{l}\text { Rt. BG infarction } \\
\text { Subcortex }\end{array}$ \\
\hline M & 55 & 4 & $\begin{array}{l}\text { Rt. MCA infarction } \\
\text { Frontal lobe }\end{array}$ \\
\hline M & 61 & 4 & $\begin{array}{l}\text { Rt. thalamic infarction } \\
\text { Subcortex }\end{array}$ \\
\hline M & 63 & 7 & $\begin{array}{l}\text { Rt. MCA infarction } \\
\text { Temporal lobe }\end{array}$ \\
\hline $\mathrm{F}$ & 57 & 2 & $\begin{array}{l}\text { Rt. cerebral infarction } \\
\text { Subcortex }\end{array}$ \\
\hline $\mathrm{F}$ & 60 & 0 & $\begin{array}{l}\text { Rt. PCA infarction } \\
\text { Temporal, Occipital lobe }\end{array}$ \\
\hline $\mathrm{F}$ & 64 & 3 & $\begin{array}{l}\text { Rt. BG, CR infarction } \\
\text { Subcortex }\end{array}$ \\
\hline M & 66 & 4 & $\begin{array}{l}\text { Rt. MCA infarction } \\
\text { Frontal, Parietal lobe }\end{array}$ \\
\hline $\mathrm{F}$ & 77 & 3 & $\begin{array}{l}\text { Rt. BG infarction } \\
\text { Subcortex }\end{array}$ \\
\hline $\mathrm{F}$ & 82 & 6 & $\begin{array}{l}\text { Rt. MCA infarction } \\
\text { Frontal, Temporal, Parietal lobe }\end{array}$ \\
\hline $\mathrm{F}$ & 83 & 5 & $\begin{array}{l}\text { Rt. CR infarction } \\
\text { Subcortex }\end{array}$ \\
\hline$F$ & 83 & 7 & $\begin{array}{l}\text { Rt. PCA infarction } \\
\text { Temporal, Parietal, Occipital lobe }\end{array}$ \\
\hline
\end{tabular}

POT=post-onset time; $B G=$ basal ganglia; $M C A=$ middle cerebral artery; $\mathrm{PCA}=$ posterior cerebral artery; $\mathrm{CR}=$ corona radiata.

Appendix 2. 발화 분석 기준

\begin{tabular}{|c|c|}
\hline 분석 기준 & 발화 내용 \\
\hline 1. 1문장 1발화를 원칙으로 한다. & $\begin{array}{l}\text { "그래서 내가 줬지. 이거를" } \\
\rightarrow \text { 그래서 내가 줬지(발화1) } \\
\rightarrow \text { 이거를(발화2) }\end{array}$ \\
\hline $\begin{array}{l}\text { 2. 시간이 경과되거나(약 } 5 \text { 초 이상) 주제의 변화가 있거나 운율의 두드러진 변화를 보일 경우 } \\
\text { 발화 수를 나눈다. }\end{array}$ & $\begin{array}{l}\text { "아니 내가(5초 경과)" 내가 울었지 } \\
\rightarrow \text { 아니 내가(발화1) } \\
\rightarrow \text { 내가 울었지(발화2) }\end{array}$ \\
\hline $\begin{array}{l}\text { 3. 같은 말이라도 다른 문맥이나 상황에서 표현되거나, 새로운 의미로 표현되었을 때에는 다른 } \\
\text { 발화로 취급한다. }\end{array}$ & $\begin{array}{l}\text { (핸드폰 보여주며) "이거 보세요" (발화1) } \\
\text { (사진을 보여주며) "이거 보세요" (발화2) }\end{array}$ \\
\hline $\begin{array}{l}\text { 4. 대상자가 자발적으로 수정하거나 새로운 의미의 첨가 없이 낱말이나 구를 반복할 때는 } \\
\text { 한 문장 안에 넣되 ( )로 구분하고 분석에서 제외시킨다. }\end{array}$ & (어쨌든)내가 그러고서(어쨌든) 뭐 그렇게 됐지 \\
\hline 5. 대상자가 습관적으로 사용하는 간투어(샘플자료의 $10 \%$ 이상 발화)는 분석에서 제외시킨다. & (어) 지금은 (어) 그걸 안 하고 있지. \\
\hline $\begin{array}{l}\text { 6. 문장을 이어가기 위한 무의미 소리나(예: 음, 어 등의 말이음) 감탄하는 소리는(예:‘아', '오') } \\
\text { 분석에서 제외시킨다. }\end{array}$ & "(오!) 너무 좋은거야” \\
\hline $\begin{array}{l}\text { 7. 외워진 자동구어는(예: 노래하기, 숫자세기) 발화로 구분하지 않고 분석에서 제외시킨다. 그 } \\
\text { 러나 자동구어가 발화 속에 내포되어 있을 경우에는 하나의 낱말로 보고 분석에 포함시킨다. }\end{array}$ & $\begin{array}{l}\text { "일, 이, 삼 , 사 오, 육, 칠” } \\
\rightarrow \text { 발화로 취급하지 않음. }\end{array}$ \\
\hline $\begin{array}{l}\text { 8. ‘그리고’나 연결어미 ‘-고’를 사용하여 계속 연결한 문장은 발화에 ‘그리고’ 또는 ‘-고’가 하나만 } \\
\text { 포함되도록 발화를 나눈다. }\end{array}$ & $\begin{array}{l}\text { “생일 축하 노래 부르고 케익 촛불 끄고 케이크 자르고 먹고 했지." } \\
\rightarrow \text { 생일 축하 노래 부르고 케익 촛불 끄고 } \\
\rightarrow \text { 케이크 자르고 먹고 했지 }\end{array}$ \\
\hline
\end{tabular}

Kim (1997), Owens (2010) 재수정. 
Appendix 3. 대화 차례 구분 기준

\begin{tabular}{|c|c|}
\hline 구분 & 예 \\
\hline $\begin{array}{l}\text { 1. 대화차례는 화자가 말을 시작하여 대화상대자가 말을 시작하기 전까지 동일한 화자가 이어간 } \\
\text { 모든 발화를 의미한다(Adams \& Bishop, 1989; Bishop, Chan, Adams, Hartley, \& Weir, } \\
\text { 2000; Bryan, Donahue, Pearl, \& Sturm, 1981; Kim \& Lee, 2007). }\end{array}$ & $\begin{array}{l}\text { 검: 주말에는 가족들이랑 어떻게 지내세요? } \\
\text { 피: 토요일 날엔 놀러도 많이 가고 친척도 보러 가요. } \\
\text { (대화차례 1) }\end{array}$ \\
\hline $\begin{array}{l}\text { 2. 대상자가 자신이 말 차례에 대화 주제를 변경하는 경우 대화차례를 나눈다(Kim \& Lee, } \\
\text { 2007; Schober-Peterson \& Johnson, 1989). }\end{array}$ & $\begin{array}{l}\text { 검: "생일에는 어떻게 지내세요?" } \\
\text { 피: "가족들이랑 밥 먹으면서 놀구요.” } \\
\text { (대화차례 1) } \\
\text { 피: “그런데 이거 언제 끝나요?” (대화차례 2) }\end{array}$ \\
\hline $\begin{array}{l}\text { 3. 동일한 주제로 대화차례를 이어갈 때, 발화 중에 3초 이상 쉼이 나타나는 경우에는 서로 다른 } \\
\text { 대화차례로 구분한다(Kim \& Lee, 2007; Lee \& Kim, 2001). }\end{array}$ & $\begin{array}{l}\text { 피: “좋아하는 거는 등산 가는 거 좋아하고요 } \\
\text { (3”) (대화차례 1) } \\
\text { 피: “그 다음 산책 가는 거 좋아해요” } \\
\text { (대화차례 2) }\end{array}$ \\
\hline $\begin{array}{l}\text { 4. 대상자가 자신의 대화차례에서 맞장구(back channel responses) 등의 낱말이나 구로 말한 } \\
\text { 경우에도 하나의 대화차례로 인정한다(Crystal, Fletcher, \& Garman, 1976). }\end{array}$ & $\begin{array}{l}\text { 피: “주로 게임을 하죠.” (대화차례 1) } \\
\text { 검: “주로 게임을 하세요?” } \\
\text { 피: “맞아요" (대화차례 2) }\end{array}$ \\
\hline $\begin{array}{l}\text { 5. 상대방의 말을 듣고 있다는 추임새로서 대상자가 단순히 고개 젓기, 머리 끄덕이기, 가리키기 } \\
\text { 등의 비구어적 행동은 대화차례로 보지 않으나, 대화 상대방의 질문이나 지시에 자연스럽게 } \\
\text { 상대방에게 대화차례를 넘기는 기능(turn passing-move function)을 가지는 발성 및 행동의 } \\
\text { 경우에는 하나의 대화차례로 간주한다(Adams \& Bishop, 1989; Bishop et al., 2000; } \\
\text { Weiner \& Goodenough, 1977). }\end{array}$ & $\begin{array}{l}\text { 피: “일 갔다가 한 숨 자고." (대화차례 1) } \\
\text { 검: “한 숨 주무세요?. (3초 후) 그리고요?" } \\
\text { 피: (고개를 가로로 저음) (대화차례 2) } \\
\text { 검: "네 알겠습니다.” }\end{array}$ \\
\hline
\end{tabular}

피=피험자; 검=검사자; $3 "=3$ 초의 시간이 지남; ( )=반복 발화.

Heo \& Lee (2012) 재수정.

Appendix 4. 주제정의 및 세부원칙

주제란 화자가 발화를 통해 제공하는 주요 정보(Owens, 2004)로, 하나의 발화 또는 동일한 어휘, 주제어(theme), 개념(concept), 구성요소로 서로 연관된 일련의 발 화로 제공될 수 있다(Schober-Peterson \& Johnson, 1993).

\begin{tabular}{|c|c|}
\hline 기준 & 예 \\
\hline $\begin{array}{l}\text { 1. 새롭게 주제가 개시된 후 새로운 주제로 변경되기 전까지 이어진 발화는 하나의 } \\
\text { 주제로 측정한다. }\end{array}$ & $\begin{array}{l}\text { 피: “지금은 핵가족화 되어서 가족들이 서로 남남처럼 산다고” } \\
\quad \text { (주제1: 핵가족) } \rightarrow \text { 주제 수 포함 }\end{array}$ \\
\hline 2. 이미 언급된 주제에 대해 내용을 첨가하거나 정교화 하는 경우에는 별도의 주제 & 검: “남남처럼 사세요?” \\
\hline 로 측정하지 않는다. & 피: “그래서 가족들이 서로 예전만큼 끈끈하지 않고 우애가 없어” \\
\hline 3. 하나의 주제가 종료되고 다른 주제로 변경되었다가 다시 이전 주제로 언급한 경 & (정교화 및 내용 첨가) $\rightarrow$ 주제 수 포함 안 함. \\
\hline \multirow[t]{4}{*}{ 우에도 새로운 주제로 측정하지 않는다. } & 피: “아, 안타깝구나." \\
\hline & $\begin{array}{l}\text { 피: “내가 지난 번에는 성묘를 갔어요” (주제2: 성묘로 변경) } \\
\quad \rightarrow \text { 주제 수 포함 }\end{array}$ \\
\hline & 검: “성묘를 가셨어요?” \\
\hline & $\begin{array}{l}\text { 피: “네 근데 성묘도 우리 식구만 가고 다들 남남처럼 안 온다고." } \\
\text { (주제1을 다시 언급) -주제 수 포함 안 함. }\end{array}$ \\
\hline
\end{tabular}

피=피험자; 검=검사자.

Park, Choi, \& Lee (2017) 재수정. 
Appendix 5. 주제운용 기술의 유형별(주제 개시, 주제 유지, 주제 변경) 정의 및 예시

\begin{tabular}{|c|c|c|}
\hline 구분 & 정의 & 예 \\
\hline 주제 개시 & $\begin{array}{l}\text { 주제 개시는 이전 주제가 종료된 후, 제시된 사진자료와 관련한 주제로 대화차 } \\
\text { 례를 자발적으로 먼저 도입한 경우 또는 이전에 개시된 주제를 다시 말한 경 } \\
\text { 우이다(Brinton \& Fujiki, 1984; Prutting \& Kirchner, 1987; Mentis, 1994). }\end{array}$ & $\begin{array}{l}\text { 검: 이제 대화를 시작해볼까요? } \\
\text { 피: 전에 나도 가족들이랑 여행을 가봤는데 }\end{array}$ \\
\hline 주제 유지 & $\begin{array}{l}\text { 주제유지는 이전 대화차례에서 개시된 주제와 관련된 내용을 반복하거나, 세밀 } \\
\text { 한 의미 또는 간단한 정보를 추가하면서 대화차례를 이어나가는 경우이다 } \\
\text { (Brinton\& Fujiki, 1984; Prutting \& Kirchner, 1987; Mentis, 1994). } \\
\text { (1) 어휘로 연결된 경우 } \\
\text { (2) 주제(theme)로 연결된 경우 } \\
\text { (3) 개념(concept)이나 구성요소로 연결된 경우 }\end{array}$ & $\begin{array}{l}\text { (1) 검:“요즘에 어르신 분들과 뮈하시면서 지내세요? } \\
\text { 피: “나이드니까 그냥 모여서 화투 치는거지.” } \\
\text { 검: “화투를 치셨어요?” } \\
\text { 피:“화투 치면 재미있어서 시간 가는 줄 몰라.” } \\
\text { (2) 검:“즐겨보시는 TV 프로그램이 어떤 건가요? } \\
\text { 피:“그냥 드라마랑 뉴스 그런 거 자주 봐요." } \\
\text { (3) 검:“좋아하시는 TV 프로그램은 뭔가요?” } \\
\text { 피: “저는 뉴스를 좋아해요." } \\
\text { 피: “뉴스에는 다양한 이야기가 많아요” }\end{array}$ \\
\hline 주제 변경 & $\begin{array}{l}\text { 주제변경은 대화를 이어나가는 도중 이전 대화차례의 주제와 연결되지 않거나 } \\
\text { 자신의 이전 발화에서 새로운 주제로 대화 주제가 바뀌는 경우이다(Brinton } \\
\text { \& Fujiki, 1984; Mentis, 1994; Prutting \& Kirchner, 1987). }\end{array}$ & $\begin{array}{l}\text { 피: 이거는 가족이네요. } \\
\text { 피: 저는 한국에 살고 있으니까 우리 한국은 효를 중요시하잖아요 } \\
\text { 피: 그 어느 나라보다도(3”) } \\
\text { 피: 저도 애들이 둘이 있는데 입양을 한번 해 보고 싶었거든요. } \\
\quad \text { (주제 변경) }\end{array}$ \\
\hline
\end{tabular}

피=피험자; 검=검사자; $3 "=3$ 초의 시간이 지남; ( )=반복 발화.

Choi \& Lee (2013) 재수정.

Appendix 6. 대화방해 지표에 따른 유형 및 정의

\begin{tabular}{lll}
\hline 구분 & \multicolumn{1}{c}{ 정의 } & \multicolumn{1}{c}{ 예 } \\
\hline 대화 중첩 & 상대방이 말하는 동안 상대방의 말에 끼어들어 방해한 대화차례를 말한다(Craig \& & 검: 식사를 * 하셨어요? \\
& Evans, 1989; Kim \& Lee, 2007; Lee \& Kim, 2011; Prutting \& Kirchner, 1987). & 피: *내가 거기에 가서 기다렸지 \\
대화 중단 & 대화 중 상대방의 말에 반응해주어야 하는 상황에 즉각적으로 이어가지 못하거나 3초 & 검: 가족 분들과 생일에는 주로 어떻게 지내세요? \\
& 이상의 시간지연, 비정상적인 쉼 혹은 무반응한 대화차례를 말한다(Prutting \& & 피: (3”) \\
& Kirchner, 1987). & 검: 생일에 어떻게 지내시죠? \\
& & 피: 무반응 \\
\hline
\end{tabular}

피=피험자; 검=검사자; *=중첩; $3 "=3$ 초의 시간이 지남; $($ )=반복 발화.

Choi \& Lee (2013) 재수정. 


\section{국문초록}

\section{우반구 손상 환자의 대화 특성}

\section{정혜영 1 김여진 ${ }^{2} \cdot$ 윤지혜 ${ }^{3} \cdot$ 최지은 ${ }^{4}$}

1한림대학교 보건과학대학원 언어병리학과, ${ }^{2}$ 한림대학교 춘천성심병원 신경과, ${ }^{3}$ 한림대학교 언어청각학부, ${ }^{4}$ 한림대학교 일반대학원 언어병리청각학과

배경 및 목적: 우반구는 언어의 사용 및 활용을 관장하는 화용적 측면을 담당하는 것으로 알려져 있다. 본 연구의 목적은 우반구 손상 환자의 대화 및 주제운용 특성을 살펴보고자 하였다. 방법: 연구 대상자는 우반구 뇌경색 환자 12 명과 성별, 연령 및 교육수준을 대응 시킨 정상 성인 12 명으로 총 24 명이었다. 구조화된 프로토콜을 사용하여 수집된 대화자료는 대화참여지표(대화차례빈도, 대화차례당 발화수), 주제운용지표(전체주제수, 주제당 대화차례빈도, 전체주제개시율, 전체주제유지율, 전체주제변경률), 대화방해지표(대화중 단율, 대화중첩률) 측면으로 분석하였다. 결과: 대화참여지표에서는 두 집단 간 유의미한 차이를 보이지 않았다. 주제운용지표에서는 우반구 손상 집단이 정상 성인 집단에 보다 더 저하된 주제운용능력을 보였다. 대화방해지표에서는 두 집단 간 유의미한 차이를 보이 지 않았다. 논의 및 결론: 본 연구는 화용언어에 어려움을 보이는 우반구 손상 환자의 대화와 주제운용능력에 대한 특성을 확인하고 우반구 환자의 평가 및 중재의 기초 근거를 제시하였다는 점에서 의의가 있다.

핵심어: 우반구 손상, 대화참여, 주제운용, 대화방해

본 논문은 2019년도 한림대학교 교비연구비에 의하여 연구되었음(No. HRF-201903-009).

본 논문은 2014년 정부(교육부)의 재원으로 한국연구재단의 지원을 받아 수행된 연구임(No. NRF-2014S1A5A2A03065709).

\section{참고문헌}

민준상, 윤지혜, 나덕렬, 이윤경(2018). 전두측두치매 환자의 대화 특성: 알츠하이머성 치매와의 비교, Communication Sciences \& Disorders, 23(1), 146-159.

박원경, 김광수(2012). 우측 대뇌 손상 환자의 작업기억 저하. 대한임상노인의학회지, 13(2), 186-193.

박윤정, 최지은, 이윤경(2017). 초등학생 아동의 대화 화제관리 능력의 발달. Communication Sciences \& Disorders, 22(1), 25-34.

백경선(2004). 우뇌 손상자의 이야기 산출에서 의미내용과 담화 구조화의 분석. 언어청각장애연구, 9(3), 72-101.

성시연, 김영태(2015). 우반구 뇌손상 환자 발화의 정보전달 및 문장 간 결속 특성, 재활복지, 19(2), 315-338.

양예원, 이윤경, 최지은, 윤지혜(2018). 후기 아동기에서 청소년기까지의 대화발달. Communication Sciences \& Disorders, 23(2), $270-278$.

우희림, 김정완(2017). 우반구 손상 환자의 인지-의사소통장애의 연구동향: 최근 10년간을 중심으로. 재활복지, 21(1), 213-231.

이미숙, 김향희(2011). 외상성 뇌손상 및 우반구 손상 환자의 인지-의사소통 능력 평가도구에 관한 문헌 고찰. 한국콘텐츠학회논문지, 11(4), $253-262$. 이효진, 김영태(2001). 단순언어장애 아동의 대화 말차례 특성. 언어청각장애연구, 6(2), 293-312.

최지은, 이윤경(2015). 학령기 고기능 자폐스펙트럼장애 아동의 주제유지능력: 수반성과 정보성을 중심으로. Communication Sciences \& Disorders, 20(3), 413-423.

허현숙, 이윤경(2012). 언어학습부진아동의 대화차례 주고받기 및 주제운용능력. 언어청각장애연구, 17(1), 66-78.

\section{ORCID}

정혜영(https://orcid.org/0000-0003-1721-5377); 김여진(https://orcid.org/0000-0002-6564-3774);

윤지혜(https://orcid.org/0000-0003-1403-2276); 최지은(https://orcid.org/0000-0002-4141-4096) 